\title{
Mechanism Analysis about How Information Seeking Strategies Affect Value Co-creation in Virtual Brand Community
}

\author{
Yihua Mao ${ }^{1, a}$, Zhongyang $\mathrm{Xu}^{1, \mathrm{~b}^{*}}$ and Jingping $\mathrm{Li}^{1, \mathrm{c}}$ \\ ${ }^{1}$ College of Civil Engineering and Architecture, Zhejiang University, Hangzhou, Zhejiang, China \\ amaoyihua@zju.edu.cn, b21412002@zju.edu.cn, 'lijingping980322@163.com
}

Keywords: Virtual brand community; Information seeking strategy; Sense of virtual community; Value co-creation; Personal innovativeness

\begin{abstract}
Value co-creation(VC) is gradually becoming a hot research topic because of its commercial significance. In order to study the happening mechanism of value co-creation behaviors(VCBs), this paper presents a mechanism path from information seeking strategies(ISSs) to VCBs in virtual brand community on the basis of literature review. This paper identifies sense of virtual community (SOVC) as an intermediate variable, defines four types of ISSs as a front variable of SOVC, and introducts personal innovativeness(PI) as a regulating variable.And our analysis show that different ISSs will significantly affect the level of SOVC, SOVC will significantly influence VCBs, and this process also will be affected by PI. This article provides a groundbreaking breakthrough point for the research about happening mechanism of VC.
\end{abstract}

\section{Introduction}

Members of virtual brand community interact with each other and form social relations for the similar even same hobbies to brand or product[1]. They can produce multiple types of participation behaviors, including ISSs and VCBs, and VC is the most commercial one of participation behaviors.Study of VC is progress, but its happening mechanism is still a blind spot.

\section{Value Co-creation}

In 2000, management gurus C.K.Prahalad \& Venkat Ramaswamy found that consumers' role is changing --from passive buy to active participation and from little contaction to closely contaction. From the perspective of managementand,they put forward that letting the consumers and producers to participate in the production process to create value, that is $\mathrm{VC}[2]$.

Through literature review, this paper argues that scholars's understanding to VC mainly includs two kinds of logic. The one is enterprises dominant logic, namely enterprise is the main part of value creation, consumers are the participators, and VC is produced in the process of consumers's participation in the production of products and services. Another is customer dominant logic, it emphasizes that the consumer is the main part of the value creation, and the enterprise participate in the process of consumers' value creation, rather than consumers get opportunitiesof involved in enterprise value creation[3,4]. Both perspectives show that $\mathrm{VC}$ created by interaction between businesses and consumers or consumers and customers. $\mathrm{VC}$ from only enterprises dominant logic or customers is narrow. So the definition of $\mathrm{VC}$ in this paper contains two kinds of logic,and $\mathrm{VC}$ is defined as the interaction and cooperation between consumers and businesses or consumers and consumers during design, development, production, consumption of the product or service and so on. 
At present, more and more many enterprises encourage consumers to participate in the production value chain of the enterprise to create value through virtual brand community. VC develops from the low involvement wich includes just helping enterprises make sure demand to the high involvement wich includes joining in enterprises' product development and design. In the process of production, consumers' participation in the enterprise research,development, design and other activities is importantly significant in reducing development costs, improving the efficiency of development, meeting consumer demand, increasing the consumer satisfaction and loyalty wich can provide reasonable, innovative ideas from the perspective of consumers for the product.In the process of service, service provision and consumption are synchronous, thus the process of interaction between consumers and service providers will greatly affect the quality of the service and the feeling of the service, such as the consumers' participation has a significant impact on the value of the services[5,6].

\section{The Influence Path from ISSs to VCBs}

In order to explain mechanism how VCBs happen in virtual brand communities and in accordance with the relevant research results, this paper constructed a inluence path model from ISSs to VCBs, as shown in Fig. 1. In the model, This paper identifies SOVC as an intermediate variable, defines four types of ISSs as a front variable of SOVC, and introducts personal innovativeness(PI) as regulating variable.

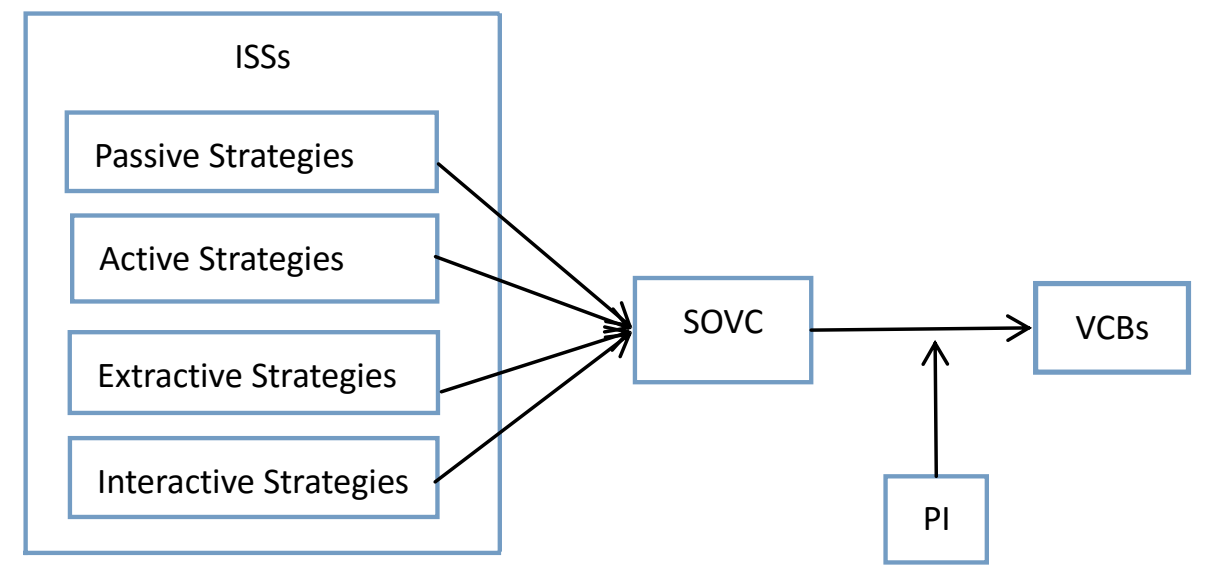

Figure 1. The Inluence Path from ISSs to VCBs

\section{Sense of Virtual Community and Information Seeking Strategy}

SOVC is that virtual-community members can sense multi-level feelings of belonging in this community[7]. Multi-level feelings include cognition, recognition, relationships, emotional attachment and obligations, as shown in tabel 1.

Cognition mainly refers to members of the community be able to recognize a user name or symbols for other members, such as head portrait. Recognition mainly refers to members not only recognize the other members, but also know which members have a same point of view, and which have a different point of view. Relationship is the third level of the virtual community feelings, specifically can be manifested as that members establish relationship with other members and often conduct private communication offline. Emotional attachment and a sense of obligation refers to members may appreciate their own loyalty to the community, and even feel an obligation to care for the community and to help the community. 
Tabel 1 Meaning of SOVC

\begin{tabular}{|l|l|}
\hline Level & Meaning \\
\hline Cognition & $\begin{array}{l}\text { Members of the community be able to recognize a user name or } \\
\text { symbols for other members, such as head portrait }\end{array}$ \\
\hline Recognition & $\begin{array}{l}\text { Members not only recognize the other members, but also know } \\
\text { which members have a same point of view, and which have a } \\
\text { different point of view }\end{array}$ \\
\hline Relationships & $\begin{array}{l}\text { Members establish relationship with other members and often } \\
\text { conduct private communication offline }\end{array}$ \\
\hline obligation and & $\begin{array}{l}\text { Members may appreciate their own loyalty to the community, and } \\
\text { even feel an obligation to care for the community and to help the } \\
\text { community }\end{array}$ \\
\hline
\end{tabular}

Social influence theory suggests that individual behaviors will be subject to the influence of others. The process of social influence can be define as obedience, identity, internalization. From the point of view of connotation, three processes of the social influence can be cover all dimensions of SOVC. In an empirical study Zhou Tao and Lu Yaohui have used social influence theory to prove that social acceptance and community norms have a significant impact on knowledge sharing behaviors in the virtual community. Many other empirical studies proved that social acceptance and community norms have a significant impact on other participation behaviors. Therefore, we will apply the social impact theory to study VCBs. And we believe that the social influence of community (in this paper means SOVC) can significantly affect behaviors of community involvement (in this paper refers to VCBs).

\section{Information Search Strategies and Sense of Virtual Community}

Information search is one of many information acts. It refers to efforts of finding the necessary information to resolve problems in the external information sources or in their memory. Uncertainty reduction theory divided the actual information seeking behavior into three categories - passive strategies, active strategy and interactive strategy. With the rapid development of the Internet, three information search strategies now already can not cover all information search strategies. So in 2002, Ramirez added a new information search strategy - extractive strategy[8,9]. This article defines four kinds of computer-mediated ISSs in virtual brand communities - passive information search strategies(PISSs), active information search strategy(AISSs), interactive information search strategies(IISSs), extractive information search strategies(EISSs). PISS refers to observating the target secretively and not contacting directly with the target for seeking information. AISS refers to the getting information about target from a third party initiatively. IISS refers to searching information for by direct interaction with the target. EISS refers to collecting information through information collections and storage technology. And there are network organizations providing large amounts of information. The organizations is just as an information search platform, do not provide their own points of view, and isdifferent from the third party platforms in AISS which usually provide their own point of view.

Evaluation theory believes that emotions arise from people's evaluation to different reactions of situations and people's emotion is not a direct response to the situation, but response to the people's evaluation whether results from situation is beneficia to their well-being. If people think one situation is conducive to achieve their goals, people will generate positive emotions. And we found that if group members think groups can improve their well-being, then the member will generally 
have positive feelings to their groups in some empirical research[10,11]. Similarl, community members can satisfy their needs by ISSs in a virtual community, then members shall have a positive emotion, that is positive SOVC. At the same time,some community involvement behaviors can also affect SOVC in a virtual community. So we believe that four kinds of ISSs will have different degrees of virtual community impact to the information seekers' SOVC because four kinds of ISSs can meet different the information needs and provide different levels interaction due to their own characteristics. That means obtaining information through PISSs will significantly affect the level of SOVC.,obtaining information through AISSs will significantly affect the level of SOVC, obtaining information through IISSs will significantly affect the level of SOVC, obtaining information through EISSs will significantly affect the level of SOVC.

\section{Adjusting Function of Innovative Individual}

In the field of technology adoption study, PI is used to explain individual different adoption and usage behaviors of innovative technology. PI is defined as an individual willingness to try new information technologies. Many previous studies have shown that PI will significantly affect the individual whether to adopt or accept new technology. Generally individuals with a high level of PI is easier to acceptproduce positive emotions to new technologies. There are two kinds of PI. one is general PI which is inherent in individual personality characteristics and will not be different from different things. Another is specific PI which is different due to different fields. Many empirical studies have shown specific PI owned high degree of interpretation and reliability[12]. Therefore, in this article, specific PI is used.

Considerable research shows that the higher level PI people have, the higher tendency to innovation behaviors individual can show,such as PI would adjust the influence progress from attitude and subjective norm to innovative behaviors intention. This article introduces VCBs into the category of innovation behaviors, and VCBs should be adjusted by PI. From a psychological point of view, people with hige level PI hope to find new things and stimulating activities by innovation behaviors. Based on this, we are willing to believe that PI will adjust the influence progress from SOVC to VCBs.

\section{Summary}

Because of the significance of VC in the virtual brand community, this article build a influence path mode from ISSs to VCBs. And through the analysis,the conclusion is that different ISSs will significantly affect the level of SOVC, and SOVC will significantly effect VCBs, this process also will be affected by the PI.

This article main contribution also includes that ISSs are applied to virtual brand community for the first time, the four kinds of ISSs in computer media are defined, SOVC is introduced to the virtual brand community which bringing new ideas for explaining other virtual brand community participation behaviors, $\mathrm{VC}$ is identified in the virtual brand community which providing a new starting point for further exploring the business value of $\mathrm{VC}$, and PI is expanded to the field of VC for the first time.

Based on the present situation and deficiency of the research of, this paper thinks that future research can be started from the following aspects:developing ISSs scale in virtual brand community; carring out an empirical study about this topic; researching the mechanism how ISSs impact on the rest of the participation behaviors in virtual brand community. 


\section{References}

[1] R. Algesheimer, U.M. Dholakia, A. Herrmann, The social influence of brand community: Evidence from European Car Clubs, J. Journal of Marketing, 2005,69(3):19-34.

[2] C.K. Prahalad, V. Ramaswamy, Co-opting customer competence, J. Harvard Business Review, 2000, 78(1):79-90.

[3] W.Z. Wu, Q.J. Chen, The forming path analysis and future research prospects about value co-creation theory, J. Journal of foreign economics and management, 2012 06:66-73+ 81 66-73.

[4] K. Heinonen, T. Strandvik, K.Mickelsson, A customer-dominant logic of service, J. Journal of Service Management. 2010,21(4):531-548.

[5] C. Gronroos, Service-dominant logic revisited; Who creates value and who co-creates, J. European Business Review, 2008a, 20(4):298-314.

[6] N. Bendapudi, R. Leone, Psychological implications of customer participation in co-production, J. Journal of Marketing, 2003,67(1):14-15.

[7] Juliana Sutanto, Atreyi Kankanhall, Bernard Cheng Yian Tan, Eliciting a Sense of Virtual Community among Knowledge Contributors, J. Journal of Academy of Marketing Science,2011, 31(1),61-73.

[8] A. Ramirez, J.B. Walther, J.K. Burgoon, M. Sunnafrank. Information-Seeking Strategies, Uncertainty, and Computer-Mediated Communication-toward a Conceptual Model, J. Human Communication Research (28:2), Apr 2002, pp 213-228.

[9] C. Luo, The impact of information search strategy to trading inuncertainty omnOnline trading, D. University of science and technology of China, 2009.

[10]T.L. Zhou,B. Yao, Study about knowledge sharing behavior in virtual community based on the social influence theory, J. Journal of management research and development, 2009, 21 (4) : $78-83$

[11]T.Y. Lou, R.W. Chu, Y.F Li, X.W. Liu, Review about the psychological mechanism of virtual community members' paticipation, J. Journal of foreign economics and management, 2011, 05:33-40.

[12]G. Roehrich, Consumer innovativeness: concepts and measure-ments, J. Journal of Business Research, 2004, 57 (6) : 671-677. 